\title{
Are there prototypical associations between time frames and aspectual values? Evidence from Greek aphasia and healthy aging
}

\begin{abstract}
Time reference, which has been found to be selectively impaired in agrammatic aphasia, is often interwoven with grammatical aspect. Dragoy and Bastiaanse (2013) investigated the relationship between time reference and aspect focusing on Russian aphasia and found that the two interact: Past reference was less impaired when tested within a perfective aspect context (compared to when tested within an imperfective aspect context), and reference to the nonpast was less impaired when tested within an imperfective aspect context (compared to when tested within a perfective aspect context). To explain this pattern, the authors argued that there are prototypical associations between time frames and aspectual values. This study explores the relationship between time reference and aspect focusing on Greek aphasia and healthy aging and using a sentence completion task that crosses time reference and aspect. The findings do not support prototypical matches between different time frames and aspectual values. Building on relevant studies (Dragoy \& Bastiaanse, 2013; Dickey, 2016), we propose that patterns of performance of healthy or language-impaired speakers on constrained tasks tapping different combinations of time frames with aspectual values should reflect the relative frequency of these combinations in a given language. The analysis of the results at the individual level revealed a double dissociation, which indicates that a given time frame-aspectual value combination may be relatively easy to process for some persons with aphasia but demanding for some others.
\end{abstract}

Keywords: time reference/tense, aspect, aphasia, prototypical associations, Greek 


\section{Introduction}

One of the most common symptoms of agrammatic aphasia is impaired verb-related morphosyntactic production. Many studies have shown that this impairment is selective, with subject-verb agreement being better preserved that tense and aspect (e.g., Fyndanis, Varlokosta, \& Tsapkini, 2012; Nanousi, Masterson, Druks, \& Atkinson, 2006; Varlokosta, Valeonti, Kakavoulia, Lazaridou, Economou, \& Protopapas, 2006; Wenzlaff \& Clahsen, 2004). Recent studies by Bastiaanse and colleagues have shown that the tense-related morphosyntactic deficit is even more selective (e.g., Bastiaanse, 2008, 2013; Bastiaanse, Bamyaci, Hsu, Lee, Yarbay Duman, \& Thompson, 2011; Martínez-Ferreiro \& Bastiaanse, 2013; Yarbay Duman \& Bastiaanse, 2009). In many languages, such as Dutch, Turkish, English, Chinese, Spanish and Catalan, agrammatic speakers were found to perform worse on past than on future or present tense (op. cit.). Moreover, it has been suggested that, in agrammatic aphasia, it is time reference, not tense, that is affected, with reference to the past being more difficult than reference to the present or future (op. cit.). To account for this pattern, Bastiaanse et al. (2011) formulated the PAst DIscourse LInking Hypothesis (PADILIH). According to the PADILIH, reference to the past is more demanding in terms of processing resources than reference to the present/future, because, unlike the latter, the former involves discourse-linking. (This theoretical assumption is based on Zagona, 2003, 2013.) The evidence for the PADILIH (Bastiaanse et al., 2011), however, is contradictory. In a recent metaanalysis, Faroqi-Shah and Friedman (2015) argued that there is only weak evidence that past tense/past reference is more impaired than future or present tense/reference in agrammatic aphasia. Similarly, Fyndanis et al. (2018a) investigated the ability of Greek- and Italian-speaking individuals with agrammatic aphasia to refer to the past and to the future and neither of the two groups of aphasic participants lent empirical support to the PADILIH (Bastiaanse et al., 2011).

Time reference through verb morphology is often interwoven with grammatical aspect. In some of the studies that provided the empirical basis for the PADILIH, time reference was confounded by aspect. In other words, the time frames compared to each other were not matched on 
aspect. Yarbay Duman and Bastiaanse (2009), for example, compared past tense/perfective aspect with future tense/imperfective aspect focusing on Turkish agrammatic aphasia. In the comparison between reference to the past and reference to the future, aspect was not kept constant. One could not rule out the possibility that in Turkish-speaking agrammatic aphasia reference to the past is more impaired than reference to the future due to the combination of past tense with perfective aspect.

Dragoy and Bastiaanse (2013) acknowledged this limitation and investigated the relationship between time reference/tense and aspect focusing on Russian aphasia. They found a significant interaction between time reference and aspect. Reference to the past was less impaired when tested within a perfective aspect context (compared to when tested within an imperfective aspect context), and reference to the nonpast was less impaired when tested within an imperfective aspect context (compared to when tested within a perfective aspect context). This pattern was accounted for in terms of prototypical and non-prototypical associations between time reference and aspectual semantics. Dragoy and Bastiaanse (2013, p. 114) adopted the view that "perfectives primarily refer to completed, past events while imperfectives prototypically describe ongoing, nonpast events". It seems reasonable that ongoing events are prototypically associated with imperfective aspect. This is also reflected in many languages, such as Russian and Greek, in which present tense morphologically encodes imperfective aspect only (see also Dickey, 2016). Dragoy and Bastiaanse (2013), however, did not limit their hypothesis to verbs referring to the past and to the present. They predicted that prototypical matches between time reference and aspect are past reference-perfective aspect and nonpast reference-imperfective aspect. By referring to nonpast, they extended the scope of their hypothesis to future reference, as they adopted the view that present and future reference are subsumed under the broader category nonpast reference. In fact, Dragoy and Bastiaanse (2013) compared present imperfective verbs with past imperfective verbs, and future perfective verbs with past perfective verbs (see figure 2 in Dragoy \& Bastiaanse, 2013).

We have to make two observations with respect to these theoretical choices and 
experimental manipulations. First, while there are convincing semantic reasons to argue for prototypical matches between past reference and perfective aspect, ${ }^{1}$ and present reference and imperfective aspect (see Dickey, 2016), there are no compelling reasons for assuming that future reference is prototypically associated with imperfective aspect. This is so because verbs referring to the future do not necessarily refer to events that are in progress. These events can be seen as ongoing or completed. These two possibilities are provided by the functional category of aspect, which is more subjective than tense (e.g., Comrie, 1976; Smith, 1997). Moreover, contrary to Dragoy and Bastiaanse's (2013) predictions, data from the Russian National Corpus (a spoken language corpus) show that, in Russian, perfective future is significantly more frequent than imperfective future (Dickey, 2016). This finding is attributed to the fact that "people tend to plan or conceive of future events in their completion (...) as opposed to being in progress and unfinished at a certain point in time" (Dickey, 2016: 344). Therefore, on semantic and psycholinguistic (in particular, frequency) grounds, one would expect aphasic speakers to perform better on future perfective verbs than on future imperfective verbs.

Second, Dragoy and Bastiaanse's (2013) hypothesis about the prototypical associations between time reference values and aspectual values would be best tested if one compared in a straightforward way (1) past reference-imperfective aspect with past reference-perfective aspect, and (2) nonpast reference-imperfective aspect with nonpast reference-perfective aspect. Crucially, in the comparison between nonpast reference-imperfective aspect and nonpast reference-perfective aspect the time frame should be kept constant. Reference to the present and reference to the future

\footnotetext{
${ }^{1}$ These semantic reasons also seem to be reflected in language acquisition data as well as in data from children with Specific Language Impairment (SLI). For instance, in Greek, a language that encodes the perfective vs. imperfective aspectual distinction in the verb, both typically developing children and children with SLI acquire perfective past earlier than imperfective past (e.g., Konstantzou, 2014; Konstantzou, van Hout, Varlokosta, \& Vlassopoulos, 2013).
} 
are often subsumed under the label nonpast, but this is done because, in many languages, reference to the present and reference to the future are usually made through morphologically similar verb forms (e.g., Greek) or identical verb forms (e.g., Italian, German, especially in the presence of temporal adverbials referring to the future). However, this does not imply that present reference and future reference are the same from a semantic point of view. For example, while in present reference the event time prototypically coincides with the utterance time, in future reference the event time is prototypically subsequent to the utterance time. Therefore, comparing future perfective with present imperfective (in order to test Dragoy and Bastiaanse's hypothesis about the prototypical association between nonpast reference and imperfective aspect) introduces a semantic confound (i.e., equation of present and future reference).

We believe that, in time reference/aspect investigations, testing present reference/tense should generally be avoided for a number of reasons. Firstly, temporal adverbials prototypically associated with present reference, such as now and today, commonly used to elicit presenttensed/present reference verbs, are also compatible with future-tensed/future reference verbs (e.g., Now I will play guitar), making it hard to reliably test reference to the present (Fyndanis et al., 2012). Secondly, in most languages, present tense only encodes imperfective aspect, so it does not allow us to reliably investigate the relationship between tense/time reference and aspect. Thirdly, present tense likely acts as the default ("unmarked") tense value, which might be due to morphosemantic (e.g., Lapointe, 1985) or psycholinguistic reasons. For example, present tense is acquired earlier than past tense or future tense (e.g., Pizzuto \& Caselli, 1994; Szagun, 1978). As a consequence, better performance on present reference than on past reference or future reference (in languages in which future reference is done through non present-tensed verbs) could be attributed to the age of acquisition advantage of present tense. The same holds true for cases of worse performance on past reference than on future reference in languages where future reference is predominantly made through present-tensed verbs (especially so in the presence of temporal adverbials; e.g., German, Italian). 
It is becoming evident, therefore, that an ideal testing ground for Dragoy and Bastiaanse's (2013) hypothesis would be provided by languages in which: i. future reference is not predominantly made through present tense; ii. both past reference and future reference morphologically encode (in the verb) the distinction between perfective and imperfective aspect; and iii. there are aspectual adverbials that are only compatible with perfective or imperfective aspect (encoded in the verb). (Otherwise, one cannot elicit specific aspectual values in sentence completion tasks.)

\section{The present study}

This study tests Dragoy and Bastiaanse's (2013) hypothesis employing data from Greek, a language that fulfills all the aforementioned criteria (for a brief background on Time Reference and Aspect in Greek, see next section). It should be noted that there are only a few published data from Greek that are relevant to this topic. These data are contradictory. Stavrakaki and Kouvava (2003) analysed samples of spontaneous speech of two Greek-speaking individuals with agrammatic aphasia, SC and $\mathrm{VF}$, and found that, within a past reference context, both participants performed worse on perfective than on imperfective aspect. The authors attributed this asymmetry to the fact that "more computational processes are required for the formation of the past perfective than the formation of past imperfective, since past imperfective (alaz-e) is more predictable from the present stem (alaz-i) than the perfective one (alak-s-e)" (Stavrakaki \& Kouvava, 2003, p. 135). Fyndanis et al. (2012), on the other hand, employed a constrained task tapping into verb-related morphosyntactic production in Greek agrammatic aphasia. The authors reported the results of two Greek-speaking individuals with agrammatic aphasia, GT and GL, on the production of perfective and imperfective aspect within past and future reference contexts. The comparisons between perfective and imperfective aspect within these two time frames did not yield significant results for either participant. To investigate the ability of their Greek-speaking participants with agrammatic aphasia to produce aspect within sentence contexts, Nanousi et al. (2006) used a forced-choice sentence completion 
task and a free sentence completion task. Although in both tasks they crossed time reference/tense with aspect, they did not report the results of the comparison between different aspectual values within a given time frame. In a similar study, Varlokosta et al. (2006) also crossed perfective and imperfective aspect with past reference and future reference in the Aspect condition, but they did not compare perfective with imperfective aspect within each time frame. This is also the case with Protopapas, Cheimariou, Economou, Kakavoulia, and Varlokosta's (2014) study, the design of which was based on Varlokosta et al. (2006).

It is worth noting that Dragoy and Bastiaanse's (2013) hypothesis does not apply only to aphasia. If there are prototypical matches between past reference and perfective aspect and between non-past reference and imperfective aspect, these matches should emerge in both aphasic and healthy (older) speakers. It is well established that healthy older people exhibit age-related decline in cognitive and language abilities (e.g., Kemper, Herman, \& Lian, 2003; Kemper, Herman, \& Liu, 2004; Kemper, Kynette, Rash, O’Brien, \& Sprott, 1989; Salthouse, 1992, 1996; Waters \& Caplan, 2005). Fyndanis, Arcara, Christidou, and Caplan (2018b), in addition to eight persons with agrammatic aphasia, tested 103 healthy adults aged 22-85 (34 of whom were older than 60) on a constrained production task tapping time reference, aspect, and subject-verb agreement, and found these healthy participants to be mildly impaired in aspect and -to a lesser extent- in time reference. Overall, the healthy participants made 313 time reference errors and 873 aspect errors.

As will be shown in the Methods section, Fyndanis et al.'s (2018b) design is appropriate for testing Dragoy and Bastiaanse's (2013) hypothesis, because it crosses time reference and aspect in both the time reference and aspect conditions. Specifically, Fyndanis et al.'s (2018b) design tests past and future reference within different aspectual contexts (i.e. within perfective and imperfective aspect contexts); and it also tests perfective and imperfective aspect within different time frames (i.e. past and future). (For more details, see Methods section.) The goal of the present study is to test Dragoy and Bastiaanse's (2013) hypothesis focusing on Fyndanis et al.'s (2018b) database and analysing their participants' performance on the Time Reference and Aspect conditions. 
Interestingly, Fyndanis et al.'s (2018b) groups of individuals with aphasia and of healthy controls differed quantitatively but not qualitatively, as both groups exhibited the same pattern of performance (Aspect $<$ Time Refefence $<$ subject-verb Agreement) and the same interaction between morphosyntactic categories and verbal working memory (in both groups, verbal working memory affected Aspect more than Time Reference, and did not affect Agreement at all). Similar patterns of performance in neurological and healthy populations have also been reported by Dick, Bates, Wulfeck, Utman, Dronkers and Gernsbacher (2001), Fyndanis et al. (2018c), and Miyake, Carpenter and Just (1994). This is consistent with the idea that pathology exacerbates trends or patterns observed in neurologically intact speakers (op. cit.). Certainly, for similar patterns in 'pathological' and healthy populations to emerge, a sufficiently large number of errors should occur in both the 'pathological' and healthy groups. Alternatively, sensitive measures should be employed (e.g., not only accuracy but also reaction times). Therefore, if at least one of the two conditions above is met, focusing on a large number of healthy speakers could serve to validate (or not) results from research on aphasia.

Dragoy and Bastiaanse's (2013) predictions are summarised in (1). As reflected in (1), the hypothesis about the prototypical matches between time reference and aspect could be tested not only in conditions tapping time reference, but also in conditions tapping aspect. (Note that in Greek, the aspectual opposition perfective-imperfective only occurs in past-tensed and future-tensed verbs; Holton, Mackridge, \& Philippaki-Warburton, 2004.)

(1) Dragoy and Bastiaanse (2013)

a. past reference within a perfective aspect context $>$ past reference within an imperfective aspect context;

b. future reference within a perfective aspect context $<$ future reference within an imperfective aspect context;

c. perfective aspect within a past reference context $>$ imperfective aspect within a past 
reference context;

d. perfective aspect within a future reference context $<$ imperfective aspect within a future reference context.

If Dragoy and Bastiaanse's (2013) hypothesis is correct, and given Fyndanis et al.'s (2018b) finding that the performance of aphasic speakers on morphosyntactic production differs from that of healthy speakers quantitatively but not qualitatively, the patterns listed in (1) should be exhibited by both aphasic and healthy participants. As aforementioned, we know from Fyndanis et al.’s (2018b) study that the healthy participants reported here made sufficiently large number of errors in the Time Reference and Aspect conditions (313 and 873, respectively), which allows for significant differences between different time frame-aspectual value combinations to be detected. We also know from Fyndanis et al. (2018b) that the healthy participants outperformed the aphasic participants in both the Time Reference and the Aspect conditions, so the present study does not address the question whether speakers with aphasia are impaired in verb-related morphosyntactic production.

Lastly, we should note that, in this study, we do not focus on the PADILIH (Bastiaanse et al., 2011) -and thus we do not test this hypothesis- because we did so in a recent cross-linguistic study (Fyndanis et al., 2018a) that reported seven of the eight Greek-speaking individuals with aphasia who also participated in the present study. That study focused on Greek and Italian agrammatic aphasia and its results were not consistent with PADILIH's predictions, as both groups of aphasic participants performed comparably on past and future reference. The constrained task used by Fyndanis et al. (2018a) did not cross time reference with aspect (i.e. there were no aspectual adverbials that could constrain the aspectual value of the target verb form); thus, it was not appropriate for investigating the relationship between time reference and aspect. 


\title{
Time Reference and Aspect in Greek
}

As mentioned above, in Greek tense/time reference interacts with aspect. In particular, the opposition between perfective and imperfective aspect is morphologically encoded in two time frames: reference to the past and reference to the future. Perfective and imperfective verb forms referring to the future are periphrastic (consisting of the future particle $\theta a$ and a monolectic verb form, e.g., $\theta$ a psíso 'I will bake-perfective' - $\theta$ a psino 'I will bake-imperfective'). The perfective and imperfective verb forms referring to the past are monolectic (e.g., épsisa '(I) baked-perfective'épsina '(I) baked-imperfective'). Present tense morphologically encodes imperfective aspect only.

\begin{abstract}
Methods
Participants

Eight Greek-speaking aphasic individuals (five female; age range: 56-90; $\mathrm{M}$ age $=69.1, \mathrm{SD}=10.7$; $\mathrm{M}$ education (number of years of formal education) $=9.3, \mathrm{SD}=4.2$ ) and 103 neurologically intact native speakers of Greek (29 male; $\mathrm{M}$ age $=50, \mathrm{SD}=19 ; \mathrm{M}$ education $=13.6, \mathrm{SD}=4.5)$ participated in the study.
\end{abstract}

All brain-damaged participants developed aphasia following cerebrovascular accidents (CVA) in the left hemisphere. Presence of aphasia and aphasia type were diagnosed on the basis of clinical presentation and the published Greek standardized version of the Boston Diagnostic Aphasia Examination-Short Form (Goodglass, Kaplan, \& Barresi, 2001; Greek version: Messinis, Panagea, Papathanasopoulos, \& Kastellakis, 2013). Aphasic participants' agrammatism was diagnosed on the basis of samples of semispontaneous speech elicited using picture description (Cookie Theft) and stroke stories. The speech samples were analyzed following the coding procedures described in Thompson, Shapiro, Tait, Jacobs, Schneider, and Ballard (1995). Individuals diagnosed with different aphasia types participated in this study as all of them had agrammatic production. This is not surprising. For example, speakers with transcortical motor aphasia presenting an agrammatic profile have already been reported in the literature (e.g., Rofes, 
Bastiaanse, \& Martínez-Ferreiro, 2014). Evidence for agrammatism was considered the combination of a relatively low proportion of grammatical sentences and a relatively reduced Mean Length of Utterance (see Faroqi-Shah \& Thompson, 2004). Demographic information and speech data for the individual aphasic participants are presented in table 1. (For more details, see Supplemental Material S1 in Fyndanis et al. (2018b), which includes the scale profile of speech/language characteristics for all the aphasic participants reported here.)

The healthy participants sampled the adult age range $22-85$ yielding a relatively uniform distribution across lifespan decades (figure 1). The Mini Mental State Examination (MMSE) (Folstein, Folstein, \& McHugh, 1975; Fountoulakis, Tsolaki, Chantzi, \& Kazis, 2000) was administered to older speakers ( $>60$ years) to exclude participants presenting signs of dementia. Only individuals who scored at least 27/30 on MMSE were included. Participants gave informed consent in accordance with the Declaration of Helsinki.

//Insert table 1 about here//

\section{Experiments}

To investigate the relationship between time reference and aspect, we developed a sentence completion task. The task consisted of 128 experimental source sentence (SS)-target sentence (TS) pairs, half of which tested time reference (within two aspectual contexts), and half aspect (within two time reference contexts). The SSs always differed from the TSs only in one feature value (time reference/tense or aspect) conveyed by an adverbial (temporal or aspectual), which was sufficient to trigger the production of the target verb form associated with the morphosyntactic category under consideration for each item (see table 2).

Of the 64 experimental SS-TS pairs in the Time Reference condition, 32 tested reference to the past and 32 tested reference to the future. In addition to the temporal adverbial (e.g., $x \theta e ́ s$ 'yesterday'), half of the past reference items also included a perfective aspect adverbial (e.g., mésa 
se mía óra 'within an hour'), and half an imperfective aspect adverbial (e.g., epi mía óra 'for an hour'). Likewise, in addition to the temporal adverbial (e.g., ávrio 'tomorrow'), half of the future reference pairs included a perfective aspect adverbial (e.g., mésa se mía óra 'within an hour'), and half included an imperfective aspect adverbial (e.g., epí mía óra 'for an hour').

Similarly, in the Aspect condition, 32 experimental pairs tapped perfective aspect and 32 imperfective aspect. Both aspect pairs were crossed with past reference and future reference adverbials, yielding four balanced Aspect subconditions: Perfective Aspect elicited in a Past Reference context $(\mathrm{n}=16)$, Perfective Aspect elicited in a Future Reference context $(\mathrm{n}=16)$, Imperfective Aspect elicited in a Past Reference context $(\mathrm{n}=16)$, and Imperfective Aspect elicited in a Future Reference context $(\mathrm{n}=16)$.

Sixteen transitive (two-place) bisyllabic regular verbs were used, all stressed on the penultimate syllable. All of them were accomplishment verbs or, at least in the sentences they occurred, they had an accomplishment status/reading, as they referred to events that had an endpoint and were incremental or gradual (Vendler, 1957). Examples of the propositions in which these verbs occurred are given in Appendix 1. Seven of the 16 verbs were verbs of alternating transitivity. The remaining verbs had a single theta-grid. The classification (shown in Appendix 2) was based on Alexiadou and Anagnostopoulou's (2004) criteria, which have also been used in a recent study on Greek aphasia that focused on verbs with alternating transitivity (Stavrakaki, Alexiadou, Kambanaros, Bostantjopoulou, \& Katsarou, 2011). ${ }^{2}$ The verbs appeared eight times overall, four times in the Time Reference condition and four times in the Aspect condition. A list of all subconditions is given in (2). The eight subconditions did not differ significantly in the frequency of the verbs they included. (In all relevant comparisons by Wilcoxon test (i.e., (i) vs. (ii), (iii) vs. (iv), (v) vs. (vi), (vii) vs. (viii)), $p>0.790$. Frequency counts were based on the Hellenic

\footnotetext{
${ }^{2}$ We thank Artemis Alexiadou for discussing with us the status of "controversial" verbs (personal communication on the $4^{\text {th }}$ of March, 2018).
} 
National Corpus; http://hnc.ilsp.gr/en/default.asp).

i. past reference within a perfective aspect context

ii. past reference within an imperfective aspect context

iii. future reference within a perfective aspect context

iv. future reference within an imperfective aspect context

v. perfective aspect within a past reference context

vi. imperfective aspect within a past reference context

vii. perfective aspect within a future reference context

viii. imperfective aspect within a future reference context

The items were mixed, pseudorandomised, and split into two lists that were administered in two sessions with a five-day interval in between. In each session, equal numbers of time reference and aspect items — evenly distributed across the eight subconditions - were tested. Within each session, the presentation order was kept constant for all participants. Sixty-four agreement items were also included in the experiment, which served as fillers in the present study. These items were evenly distributed in the two sessions. Participants were auditorily presented with a SS and the beginning of the TS, and were asked to orally complete the TS producing the missing verb phrase. Examples of the eight subconditions of the Time Reference and Aspect conditions are provided in table 2.

\author{
//Insert table 2 about here//
}

\title{
Data analysis
}

For the statistical analysis, we employed the $\mathrm{R}$ programming language and environment for statistical computing and graphics (R Core Team, 2014). To analyse results at the individual level, 
we employed Fisher's exact test for count data. The package lme4 (Bates, Maechler, Bolker, \& Walker, 2015) has been employed for fitting generalized mixed-effect models to the relevant datasets of the aphasic and healthy speakers' groups (i.e. Past Reference subcondition of the Time Reference condition, Future Reference subcondition of the Time Reference condition, Aspect within a Past Reference context (subcondition 1 of Aspect condition), Aspect within a Future Reference context (subcondition 2 of Aspect condition)). We fitted two generalized mixed-effect models to the relevant datasets. Model 1 included Aspect (two levels: Perfective Aspect, Imperfective Aspect) ${ }^{3}$ and Alternating Transitivity (two levels: Plus, Minus) as fixed effects, their interaction, Subjects and Items as random effects, and Aspect as by-Subject random slope. Model 2 included Aspect (two levels: Perfective Aspect, Imperfective Aspect) and Alternating Transitivity (two levels: Plus, Minus) as fixed effects, the interaction between the two, and Subjects and Items as random effects. Model selection was based on the Akaike Information Criterion (see Burnham \& Anderson, 2004). The inclusion of alternating transitivity as a covariate was motivated by the fact that in agrammatic aphasia verbs with complex lexical entries are more difficult to produce than verbs with simple lexical entries (see, for example, Thompson (2003) and references therein). Verbs that can appear as both transitive and intransitive (i.e. verbs of alternating transitivity) have a more complex lexical entry than verbs that "behave" as transitive only.

\footnotetext{
${ }^{3}$ The name of these levels may be misleading in the case of the time reference datasets. In fact, in both time reference datasets, the model compared "time reference performance" in two different aspectual contexts keeping the time frame constant. In the dataset of the past reference subcondition of the time reference condition, the dependent variable was accuracy on past reference within a perfective aspect context and on past reference within an imperfective aspect context. Likewise, in the dataset of the future reference subcondition of the time reference condition, the dependent variable was accuracy on future reference within a perfective aspect context and on future reference within an imperfective aspect context.
}

URL: http://mc.manuscriptcentral.com/tclp Email: mjb0372@louisiana.edu 
We also wanted to check if factors that are known to be predictors of accuracy on morphosyntactic production or on formal testing situations in general, such as verbal working memory (e.g., Fyndanis et al., 2018b; Kok, van Doorn, \& Kolk, 2007), age (e.g., Kemper et al., 1989, 2003, 2004; Fyndanis et al., 2018b) and education (e.g., Ostrosky-Solis, Ardila, Roselli, Lope-Arango, \& Uriel-Mendoza, 1998; Simos, Kasselimis, \& Mouzaki, 2011), interact with the two levels of the dependent variable in our datasets. The answer to this question could inform the interpretation of the results of the mixed-effect models fitted to test Dragoy and Bastiaanse's (2013) hypothesis. To this end, we fitted generalized linear models including the interaction between the dependent variable and each one of the afore-mentioned factors (i.e. verbal working memory, age, and education) to the four datasets of the healthy participants. We did not fit these models to the datasets of the aphasic participants because datasets consisting of eight participants only do not lend themselves for investigating the role of continuous variables in morphosyntactic production. It should be noted that initially we tried to fit generalized mixed-effect models including the interactions above to the datasets of the 103 healthy participants, but these models did not converge. This is not surprising given the inclusion of continuous variables in the interactions. Details about the tasks used to measure verbal working memory are included in Fyndanis et al. (2018b). (For a qualitative error analysis, see also Fyndanis et al.'s (2018b) study.)

\section{Results}

\section{Time Reference condition}

At the individual level, no aphasic participant exhibited dissociations between the relevant subconditions (in all comparisons by Fisher's exact test, n.s.) (table 3). As shown in figure 2, the aphasic participants performed comparably on past reference within perfective and imperfective aspect contexts (64\% and $60 \%$ correct, respectively), as well as on future reference within perfective and imperfective aspect contexts (71\% and $70 \%$ correct, respectively). The results of Model 2 fitted to the aphasic participants' dataset Past Reference subcondition of Time Reference 
condition are presented in table 4. There was no main effect of Aspect, meaning that the difference between past reference within a perfective aspect context and past reference within an imperfective aspect context was not significant. There was no main effect of Alternating Transitivity either, and Aspect did not interact with Alternating Transitivity. The results of Model 2 fitted to the aphasic participants' dataset Future Reference subcondition of Time Reference condition are presented in table 5. Again, the difference between future reference within a perfective aspect context and future reference within an imperfective aspect context was not significant, and there was no main effect of Alternating Transitivity and no interaction between Aspect and Alternating Transitivity.

\author{
//Insert table 3 about here// \\ //Insert table 4 about here// \\ //Insert figure 2 about here//
}

//Insert table 5 about here//

Overall, the group of healthy participants made 313 errors in the Time Reference condition. The performance of this group on the four subconditions of the Time Reference condition is presented in figure 3. Model 2 was successfully fitted to the relevant datasets. The results of this model fitted to the healthy participants' Past Reference subcondition of the Time Reference condition are presented in table 6. There was no main effect of Aspect and Alternating Transitivity, and no interaction between the two. The healthy speakers performed $96 \%$ correct in both aspectual contexts. Likewise, the results of Model 2 fitted to the healthy participants' Future Reference subcondition of the Time Reference condition showed no main effect of Aspect and Alternating Transitivity and no interaction between the two (see figure 3 and table 7). The healthy speakers 
performed $94-95 \%$ correct in both aspectual contexts.

Finally, the results of the additional models including the interactions between the two levels of the dependent variable and verbal working memory, age and education (fitted to the past reference and future reference datasets of the healthy participants) are presented in tables 8-9. None of these variables interacted with the dependent variable in either dataset. However, a main effect of age, education and working memory was found in both datasets. The younger the participant, the higher their education, and the greater their verbal working memory capacity, the better their performance on past or future reference was.

\author{
//Insert figure 3 about here// \\ //Insert table 6 about here// \\ //Insert table 7 about here// \\ //Insert table 8 about here// \\ //Insert table 9 about here//
}

\title{
Aspect condition
}

At the individual level, four of the eight aphasic participants exhibited dissociations in the Aspect condition (table 10). P1, P7 and P8 made up a double dissociation: P1 fared significantly better on imperfective aspect tested within a future reference context than on perfective aspect tested within a future reference context (Fisher's exact test, $p<0.001$ ), and P7 and P8 exhibited the opposite pattern (Fisher's exact test, $p=0.016$ and $p<0.001$ for P7 and P8, respectively.) Moreover, P3 fared significantly better on perfective aspect tested within a past reference context than on 
imperfective aspect tested within a past reference context (Fisher's exact test, $p=0.023$ ). All other comparisons did not yield significant differences.

//Insert table 10 about here//

The results of the aphasic and healthy participants on the four subconditions of the Aspect condition are given in figure 4 and figure 5, respectively. The results of Model 1 fitted to the aphasic participants' dataset Aspect within a Past Reference context are presented in table 11. As a group, aphasic participants performed 54\% and 42\% correct on Perfective and Imperfective Aspect respectively, but this difference was not significant. Thus, there was no main effect of Aspect in this dataset. Model 1 showed that there was no main effect of Alternating Transitivity either, nor an interaction between Alternating Transitivity and Aspect. The results of Model 1 fitted to the aphasic participants' dataset Aspect within a Future Reference context are given in table 12. Again, there was no main effect of Aspect (32\% and 30\% correct on Perfective and Imperfective Aspect within a Future Reference context, respectively), no main effect of Alternating Transitivity, and no interaction between the two.

\author{
//Insert figure 4 about here// \\ //Insert figure 5 about here// \\ //Insert table 11 about here// \\ //Insert table 12 about here//
}

The group of healthy participants made 873 errors in the Aspect condition. The results of 
Model 1 fitted to the healthy participants' datasets Aspect within a Past Reference context and Aspect within a Future Reference context are presented in table 13 and table 14, respectively. In both datasets, there were no significant differences between perfective and imperfective aspect. Within the past reference context of the Aspect condition, the healthy participants performed $91 \%$ and $88 \%$ correct on perfective and imperfective aspect, respectively. Within the future reference context of the Aspect condition, the healthy participants performed $85 \%$ and $83 \%$ correct on perfective and imperfective aspect, respectively (figure 5). Moreover, there was no main effect of Alternating Transitivity and no interaction between Aspect and Alternating Transitivity in either dataset.

Lastly, the results of the additional models including the interactions between the two levels of the dependent variable and verbal working memory, age and education (fitted to the 'aspect within a past reference context dataset' and to the 'aspect within a future reference context dataset' of the healthy participants) are given in tables $15-16$. Just like in the time reference conditions, although a main effect of age, education and working memory was found in both datasets, none of these variables interacted with the dependent variable in either dataset. As far as the main effects of these variables are concerned, again, the younger the participant, the higher her/his education, and the greater her/his verbal working memory capacity, the better her/his performance on aspect was.

//Insert table 13 about here//

//Insert table 14 about here//

//Insert table 15 about here//

//Insert table 16 about here// 


\section{Discussion}

This study addressed whether there are prototypical associations between time frames and aspectual values. In particular, it tested Dragoy and Bastiaanse's (2013) hypothesis that there are prototypical matches between past reference and perfective aspect and between non-past reference and imperfective aspect. We focused on Greek - a language that morphologically encodes the aspectual opposition perfective-imperfective within past reference and future reference - and administered a sentence completion task to eight aphasic speakers and 103 healthy individuals. This task elicited verb forms referring to the past and to the future within both perfective and imperfective aspect contexts (Time Reference condition). It also elicited perfective and imperfective aspect within both past and future reference contexts (Aspect condition). Dragoy and Bastiaanse's (2013) hypothesis would predict the combination of past reference with perfective aspect to elicit better performance than the combination of past reference with imperfective aspect; and the combination of future reference with imperfective aspect to elicit better performance than the combination of future reference with perfective aspect. These predictions should apply to both the Time Reference and Aspect conditions, provided that time reference and aspect are crossed in both conditions. Although Dragoy and Bastiaanse's (2013) hypothesis was formulated to capture data from aphasia, we tested both aphasic speakers and a large number of healthy aging people for the following reason: if prototypical associations between time frames and aspectual values exist, these should emerge in all populations that make a sufficiently large number of errors in relevant conditions. Relatedly, there is evidence that, at least in morphosyntactic production, the performance of healthy speakers differs from that of neurologically affected speakers such as persons with aphasia or individuals with Alzheimer's disease quantitatively and not qualitatively (e.g., Fyndanis et al., 2018b; 2018c). Thus, if this is true, the results of a large group of healthy participants presenting enough variability in cognitive and language abilities could serve to validate or not results from small groups of speakers with aphasia. We will first discuss the individual data of the aphasic participants, and subsequently we will discuss the main findings at the group level. 


\section{Discussion of individual results}

Half of the aphasic participants exhibited dissociations, and all of them emerged in the Aspect condition. Importantly, three aphasic participants (P1, P7 and P8) made up a double dissociation: P1 performed significantly better on imperfective aspect tested within a future reference context than on perfective aspect tested within a future reference context, whereas P7 and P8 exhibited the opposite pattern. Another aphasic participant, P3, fared significantly better on perfective aspect tested within a past reference context than on imperfective aspect tested within a past reference context. The patterns exhibited by P1 and P3 were consistent with Dragoy and Bastiaanse's (2013) hypothesis. However, P7 and P8 exhibited the opposite pattern to that predicted by this hypothesis. Hence, the individual data of the aphasic participants are mixed. The fact that six out of eight aphasic participants exhibited either dissociations not predicted by Dragoy and Bastiaanse's (2013) hypothesis or no dissociations at all indicates that, for the most part, the individual data of the aphasic participants are not consistent with this hypothesis. The double dissociation that emerged within the group of aphasic participants, however, demonstrates that a given time frame-aspectual value combination may be relatively easy to process for some speakers with aphasia but demanding for some others. Therefore, studies investigating tense/time reference or aspect in aphasia should ensure that the one morphosyntactic/morphosemantic category is not confounded by the other.

One could assume that P1, P7, and P8 differed in the site of lesion, which might have resulted in the observed double dissociation. Unfortunately, precise lesion data for the aphasic participants reported here are not available. However, Fyndanis et al. (2018b) provided evidence that, at least in verb-related morphosyntactic production, variability across aphasic participants is not necessarily attributable to "neurological differences". This is so because, in Fyndanis et al.'s (2018b) study, the same variety of patterns of performance on subject-verb agreement, time reference and aspect were exhibited by aphasic and healthy speakers. Inspired by this finding, and given that, in the present study, the double dissociation emerged in the "aspect within a future reference context" aphasia dataset, we checked the individual data of the healthy participants in the 
corresponding dataset. Consistent with Fyndanis et al. (2018b), we found that also healthy participants showed dissociations between perfective and imperfective aspect, and, importantly, they also made up a double dissociation. Specifically, six healthy participants fared significantly better on perfective aspect tested within a future reference context than on imperfective aspect tested within a future reference context, and one showed the opposite pattern. This similarity between the aphasic group and the group of healthy participants suggests that the double dissociation observed within the aphasic group may not be due to neurological differences between the aphasic participants.

An anonymous reviewer argued that factors such as working memory, age and education might have played a role in the dissociations observed. The models including the interactions between the two levels of the dependent variable in each dataset and working memory, age and education showed that none of these variables interacted with the dependent variable in any of the four datasets of the healthy participants. (Recall that the dependent variables in the four datasets were (i) accuracy on perfective and imperfective aspect elicited within a past reference context, (ii) accuracy on perfective and imperfective aspect elicited within a future reference context, (iii) accuracy on past reference elicited within perfective and imperfective aspect contexts, and (iv) accuracy on future reference elicited within perfective and imperfective aspect contexts.) Therefore, the data of the healthy participants are not consistent with the idea that working memory, age or education may differentially affect perfective and imperfective aspect, which in turn suggests that none of these variables is very likely to have given rise to the double dissociation observed within the aphasic and the healthy participants' groups. However, we cannot rule out the possibility that one or more of the factors above (e.g., working memory or education) had a differential effect on the dependent variable (e.g., accuracy on perfective and imperfective aspect elicited within a future reference context) in some participants only, and that the direction of this differential effect differed across participants. Nevertheless, it is hard to establish which factor gives rise to a dissociation between perfective and imperfective aspect in each participant. 


\section{Discussion of group results}

The group results do not lend support to Dragoy and Bastiaanse's (2013) hypothesis, as none of the predictions that follow from this hypothesis was borne out. Specifically, none of the relevant comparisons (i.e. (1) past reference within a perfective aspect context vs. past reference within an imperfective aspect context; (2) future reference within a perfective aspect context vs. future reference within an imperfective aspect context; (3) perfective aspect within a past reference context vs. imperfective aspect within a past reference context; (4) perfective aspect within a future reference context vs. imperfective aspect within a future reference context) yielded significant differences for either group. Moreover, there was no interaction between Aspect and Alternating Transitivity in any of the relevant datasets, meaning that, even if dissociations had emerged between the two levels of the dependent variable, these dissociations would not have been attributable to a differential effect of Alternating Transitivity on the two levels of the dependent variable. We are confident that these results are valid because the same patterns emerged in both groups. Results, therefore, suggest that there is no significant interaction between time reference and aspect. The fact that the two groups exhibited the same patterns of performance (although the healthy participants outperformed the aphasic participants) is consistent with the view that, at least in morphosyntactic production, the linguistic behavior of healthy speakers does not differ qualitatively from that of cognitively/language-impaired individuals (e.g., Dick et al., 2001; Fyndanis et al., 2018b; 2018c; Miyake et al., 1994).

We also found that there was no interaction between verbal working memory, age or education, on the one hand, and (the different values of) time reference or aspect, on the other hand. That means that, even if dissociations had emerged between the two levels of the dependent variable in the models fitted to test Dragoy and Bastiaanse's (2013) hypothesis, these dissociations could not have resulted from a differential effect of verbal working memory, age or education on the two levels of the dependent variable. However, a main effect of age, education, and working memory emerged in all four datasets, showing that the younger the participant, the higher their 
education, and the greater their verbal working memory capacity, the better their performance on time reference and aspect. This is consistent with studies reporting evidence for the important role of verbal working memory, age and education in aspects of sentence production or in formal language testing in general (e.g., Fyndanis et al., 2018b; Kemper et al., 1989, 2003, 2004; Kok et al., 2007; Ostrosky-Solis et al., 1998; Simos et al., 2011).

It is worth noting that Dragoy and Bastiaanse (2013) made an explicit claim and two implicit assumptions. The explicit claim was that there are prototypical semantic associations between time frames and aspectual values. The first implicit claim was that these prototypical associations are reflected in speakers' performance on constrained tasks tapping different combinations of time frames with aspectual values. (Note that Dragoy and Bastiaanse based their claim on their participants' performance on constrained tasks.) The second implicit assumption was that the prototypical semantic associations between different time frames and aspectual values are universal. (The scope of their claim was broad, not restricted to Russian.) Our results are consistent with three possibilities: (1) There are no prototypical semantic associations between time frames and aspectual values. (2) Prototypical semantic associations between time frames and aspectual values do exist, but they are not reflected in speakers' patterns of performance. (3) Prototypical semantic associations between time frames and aspectual values exist and are reflected in speaker's patterns of performance, but they are language-specific. Similar studies should be carried out in many relevant languages to help adjudicate between the three possibilities above.

As anonymous reviewer assumed that, if prototypical semantic associations between different time frames and aspectual values are language-specific, this specificity may result from across-language differences in the morphological/lexical means whereby aspect is encoded in verb forms referring to a given time frame. This possibility is relevant to the morphology-semantics interface. Indeed, Greek and Russian differ in the way perfective and imperfective aspect is encoded in verbs referring to the future. While in Greek both future perfective and future imperfective are expressed via monolectic verb forms, in Russian future perfective is expressed via 
monolectic verb forms and future imperfective is expressed via periphrastic verb forms (see Dragoy \& Bastiaanse, 2013). However, this difference in the way Greek and Russian encode aspect could not relate to the findings of our study, because the results of our and Dragoy and Bastiaanse's studies are not directly comparable. This is so because our study compared past perfective with past imperfective and future perfective with future imperfective, whereas Dragoy and Bastiaanse's design only allows for the comparisons between past perfective and past imperfective and between present imperfective and future perfective. The relationship between time reference and aspect should be explored by keeping the time frames constant. The semantics of present reference differs from that of future reference. Ideally Dragoy and Bastiaanse should have left present reference out and should have compared future perfective with future imperfective. We understand that such a comparison would involve a confound, as in Russian future perfective is expressed via monolectic verb forms, whereas future imperfective is expressed via periphrastic verb forms. However, given that these two "ideal" comparisons (i.e. past perfective vs. past imperfective and future perfective vs. future imperfective) are possible in Greek while keeping the morphological factor constant, ${ }^{4}$ exploring (in a future study) the relationship between time reference and aspect in Greek and Russian with the same design could address the question whether language-specific factors (e.g., morphological means of expressing specific time frame-aspectual value combinations) can affect participants' performance and give rise to language-specific prototypical associations between different time frames and aspectual values.

The group results are not consistent with the Russian corpus data discussed in Dickey (2016) either. Based on these data, Dickey (2016: 344) suggested that "people tend to plan or conceive of future events in their completion (...) as opposed to being in progress and unfinished at

\footnotetext{
${ }^{4}$ Note that in Greek the comparison "past perfective vs. past imperfective" involves monolectic verb forms only, and the comparison "future perfective vs. future imperfective" involves periphrastic verb forms only.
} 
a certain point in time". The implicit assumption of Dickey is that the relative frequency of occurrence of verb forms encoding different combinations of time frames and aspectual values reflects a hierarchy of the speakers' preferences regarding the "aspectual view" (perfective vs. imperfective) of past and future events. As mentioned above, one of the implicit assumptions of Dragoy and Bastiaanse (2013) is that prototypical semantic associations between different time frames and aspectual values are reflected in speakers' performance on constrained tasks tapping different combinations of time frames with aspectual values. A hypothesis that arises from the two assumptions is that the relative frequency of these combinations should be reflected in patterns of performance of healthy or language-impaired speakers on constrained tasks tapping different combinations of time frames and aspectual values. Future research should test this hypothesis. Ideally, large spoken corpora should be used to determine what is the relative frequency of occurrence of different combinations of time frames with aspectual values in different languages, and then constrained tasks tapping into these combinations should be administered to sufficiently large numbers of healthy and language-impaired individuals to check if indeed the speakers' pattern of performance reflects the "frequency hierarchy" determined by corpora. According to this hypothesis, and on the basis of the present results, we would expect Greek verb forms referring to the past and encoding perfective aspect to be as frequent as verb forms referring to the past and encoding imperfective aspect. Similarly, we would expect Greek verb forms referring to the future and encoding perfective aspect to be as frequent as Greek verb forms referring to the past and encoding imperfective aspect.

A related interesting question that should be addressed in future research is whether all languages that morphologically encode the aspectual opposition perfective-imperfective in different time frames feature the same frequency pattern. On the assumption that the tentative hypothesis put forward above is valid, the discrepancy between our results, on the one hand, and the data reported by Dragoy and Bastiaanse (2013) and discussed in Dickey (2016), on the other hand, suggests that the frequency pattern varies across languages. 
These investigations are expected to have important methodological implications in psycholinguistics and cognitive (neuro)psychology. Insights on the possible interaction between time reference and aspect in a given language will inform future methods for investigating the ability of neurologically affected and healthy speakers to refer to different time frames and to produce different aspectual values, ensuring that design artifacts will be eliminated to the extent possible. Teasing apart time reference and aspect is also expected to have clinical implications, as this will allow us to make more precise measurements of the ability of neurologically affected speakers to process these two morphosyntactic/morphosemantic categories. Increasing the precision of such assessments will allow the clinician to tailor the therapeutic program to the specific needs of their clients.

\section{Acknowledgements}

This section will be written after the article has been accepted.

\section{Declaration of Interest}

The authors report no conflicts of interest.

\section{Funding}

This section will be written after the article has been accepted.

\section{References}

Alexiadou, A., \& Anagnostopoulou, E. (2004). Voice morphology in the causative-inchoative alternation: Evidence for a non-unified structural analysis of unaccusatives. In A. Alexiadou, E. Anagnostopoulou, \& M. Everaert (Eds.), The unaccusativity puzzle (pp. 114 136). Oxford, UK: Oxford University Press.

Bastiaanse, R. (2008). Production of verbs in base position by Dutch agrammatic speakers: 
Inflection versus finiteness. Journal of Neurolinguistics, 21, 104-119. doi: 10.1016/j.jneuroling.2006.10.006

Bastiaanse, R. (2013). Why reference to the past is difficult for agrammatic speakers. Clinical Linguistics and Phonetics, 27, 244-263. doi: 10.3109/02699206.2012.751626

Bastiaanse, R., Bamyaci, E., Hsu, C., Lee, J., Yarbay Duman, T., \& Thompson, C. K. (2011). Time reference in agrammatic aphasia: a cross-linguistic study. Journal of Neurolinguistics, 24, 652-673. doi: 10.1016/j.jneuroling.2011.07.001

Bates, D., Maechler, M., Bolker, B., \& Walker, S. (2015). Fitting linear mixed-effects models using lme4. Journal of Statistical Software, 67, 1-48. doi: 10.18637/jss.v067.i01

Burnham, K. P., \& Anderson, D. R. (2004). Multimodel inference: Understanding AIC and BIC in model selection. Sociological Methods and Research, 33, 261-304. doi: 10.1177/ 0049124104268644

Comrie, B. (1976). Aspect. New York, NY: Cambridge University Press.

Dick, F., Bates, E., Wulfeck, B., Utman, J. A., Dronkers, N., \& Gernsbacher, M. A. (2001). Language deficits, localization, and grammar: Evidence for a distributive model of language breakdown in aphasic patients and neurologically intact individuals. Psychological Review, 108, 759-788. doi: 10.1037/0033-295X.108.4.759

Dickey, S. (2016). Lexical and grammatical aspect. In N. Riemer (Ed.), The Routledge Handbook of Semantics (pp. 338-353). London/New York: Routledge.

Dragoy, O., \& Bastiaanse, R. (2013). Aspects of time: Time reference and aspect production in Russian aphasic speakers. Journal of Neurolinguistics, 26, 113-128.

doi: 10.1016/j.jneuroling.2012.05.003

Faroqi-Shah, Y., \& Friedman, L. (2015). Production of verb tense in agrammatic aphasia: A metaanalysis and further data. Behavioural Neurology, vol. 2015, article ID 983870, 15 pages. doi: $10.1155 / 2015 / 983870$

Faroqi-Shah, Y., \& Thompson, C. K. (2004). Semantic, lexical, and phonological influences on the 
production of verb inflections in agrammatic aphasia. Brain and Language, 89, 484-498. doi: $10.1016 /$ j.bandl.2003.12.006

Fyndanis, V., Arcara, G., Capasso, R., Christidou, P., de Pellegrin, S., Gandolfi, M., Messinis, L., Papathanasopoulos, P., Panagea, E., Smania, N., Semenza, C., \& Miceli, G. (2018a). Time reference in Greek- and Italian-speaking agrammatic aphasia: A cross-linguistic test of the PAst DIscourse LInking Hypothesis. Clinical Linguistics and Phonetics. doi: $10.1080 / 02699206.2018 .1445291$

Fyndanis, V., Arcara, G., Christidou, P., \& Caplan, D. (2018b). Morphosyntactic production and verbal working memory: Evidence from Greek aphasia and healthy aging. Journal of Speech, Language and Hearing Research. doi: 10.1044/2018_JSLHR-L-17-0103

Fyndanis, V., Arfani, D., Varlokosta, S., Burgio, F., Maculan, A., Miceli, G., Arcara, G., Palla, F., Cagnin, A., Papageorgiou, S., \& Semenza, C. (2018c). Morphosyntactic production in Greekand Italian-speaking individuals with probable Alzheimer's disease: Evidence from subjectverb agreement, tense/time reference, and mood. Aphasiology, 32, 61-87.

doi: $10.1080 / 02687038.2017 .1358352$

Fyndanis, V., Varlokosta, S., \& Tsapkini, K. (2012). Agrammatic production: Interpretable features and selective impairment in verb inflection. Lingua, 122, 1134-1147. doi: 10.1016/j.lingua.2012.05.004

Folstein, M., Folstein, S., \& McHugh, P. R. (1975). Mini Mental State: A practical method for grading the cognitive state of patients for the clinician. Journal of Psychiatric Research, 12, 189-198. doi: 10.1016/0022-3956(75)90026-6

Fountoulakis, K. N., Tsolaki, M., Chantzi, H., \& Kazis, A. (2000). Mini Mental State Examination (MMSE): A validation study in Greece. American Journal of Alzheimer's Disease and Other Dementias, 15, 342-345. doi: 10.1177/153331750001500604

Goodglass, H., Kaplan, E., \& Barresi, B. (2001). Boston Diagnostic Aphasia Examination: Short Form Record Booklet (3rd ed). Boston, MA: Lippincott Williams and Wilkins. 
Holton, D., Mackridge, P., \& Philippaki-Warburton, I. (2004). Greek: An Essential Grammar of the Modern Language. London: Routledge.

Kemper, S., Herman, R., \& Lian, C. (2003). Age differences in sentence production. Journal of Gerontology: Psychological Sciences, 58B, P260-P268. doi: 10.1093/geronb/58.5.P260

Kemper, S., Herman, R. E., \& Liu, C.-J. (2004). Sentence production by young and older adults in controlled contexts. Journal of Gerontology: Psychological Sciences, 59B, P220-P224. doi: 10.1093/geronb/59.5.P220

Kemper, S., Kynette, D., Rash, S., O’Brien, K., \& Sprott, R. (1989). Life span changes to adults' language: Effects of memory and genre. Applied Psycholinguistics, 10, 49-66. doi: $10.1017 / \mathrm{S} 0142716400008419$

Kok, P., van Doorn, A., \& Kolk, H. (2007). Inflection and computational load in agrammatic speech. Brain and Language, 102, 273-283. doi: 10.1016/j.bandl.2007.03.001

Konstantzou, K. (2014). Acquisition of Tense and Aspect: Evidence from Production and Comprehension Tasks. Unpublished PhD thesis. University of Athens. (in Greek)

Konstantzou, K., van Hout, A., Varlokosta, S., \& Vlassopoulos, M. (2013). Perfective imperfective: Development of aspectual distinctions in Greek specific language impairment. Linguistic Variation, 13, 187-216. doi: 10.1075/lv.13.2.03kon

Lapointe, S. G. (1985). A theory of verb form use in the speech of agrammatic aphasics. Brain and Language, 24, 100-155. doi: 10.1016/0093-934X(85)90100-2

Martínez-Ferreiro, S., \& Bastiaanse, R. (2013). Time reference in Spanish and Catalan non-fluent aphasia. Lingua, 137, 88-105. doi: 10.1016/j.lingua.2013.09.003

Messinis, L., Panagea, E., Papathanasopoulos, P., \& Kastellakis, A. A. (2013). The assessment of aphasia and related disorders: Adaptation and validation of the Boston Diagnostic Aphasia Examination-Short Form in Greek. Patras, Greece: Gotsis.

Miyake, A., Carpenter, P. A., \& Just, M. (1994). A capacity approach to syntactic comprehension 
disorders: Making normal adults perform like aphasic patients. Cognitive Neuropsychology, 11, 671-717. doi: 10.1080/02643299408251989

Nanousi, V., Masterson, J., Druks, J., \& Atkinson, M. (2006). Interpretable vs. uninterpretable features: Evidence from six Greek-speaking agrammatic patients. Journal of Neurolinguistics, 19, 209-238. doi: 10.1016/j.jneuroling.2005.11.003

Ostrosky-Solis, F., Ardila, A., Roselli, M., Lope-Arango, G., \& Uriel-Mendoza, V. (1998). Neuropsychological test performance in illiterate subjects. Archives of Clinical Neuropsychology, 13, 645-660. doi: 10.1016/S0887-6177(97)00094-2

Protopapas, A., Cheimariou, S., Economou, A., Kakavoulia, M., \& Varlokosta, S. (2014).

Functional categories related to verb inflection are not differentially impaired in Greek aphasia. Language and Cognition, 8, 124-141. doi: 10.1017/langcog.2014.46

Pizzuto, E., \& Caselli, M. C. (1994). The acquisition of Italian verb morphology in a crosslinguistic perspective. In Y. Levy (Ed.), Other children, other languages: Issues in the theory of language acquisition (pp. 137-188). Hillsdale, NJ: Lawrence Erlbaum Associates.

R Core Team (2014). R: A language and environment for statistical computing. R Foundation for Statistical Computing, Vienna, Austria. URL http://www.R-project.org/.

Rofes, A., Bastiaanse, R., \& Martínez-Ferreiro, S. (2014). Conditional and future-tense impairment in non-fluent aphasia. Aphasiology, 28, 99-115. doi: 10.1080/02687038.2013.850650

Salthouse, T. A. (1992). Mechanisms of Age-Cognition Relations in Adulthood. Hillsdale, N.J.: Erlbaum.

Salthouse, T. A. (1996). The processing-speed theory of adult age differences in cognition. Psychological Review, 103, 403-428. doi: 10.1037/0033-295X.103.3.403

Simos, P. G., Kasselimis, D., \& Mouzaki, A. (2011). Age, gender, and education effects on vocabulary measures in Greek. Aphasiology, 25, 475-491. doi: $10.1080 / 02687038.2010 .512118$

Smith, C. S. (1997). The parameter of aspect (2nd ed.). Dordrecht: Kluwer Academic Publishers. 
Stavrakaki, S., Alexiadou, A., Kambanaros, M., Bostantjopoulou, S., \& Katsarou, Z. (2011). The production and comprehension of verbs with alternating transitivity by patients with nonfluent aphasia. Aphasiology, 25, 642-668. doi: 10.1080/02687038.2010.542248

Stavrakaki, S., \& Kouvava, S. (2003). Functional categories in agrammatism: Evidence from Greek. Brain and Language, 86, 129-141. doi: 10.1016/S0093-934X(02)00541-2

Szagun, G. (1978). On the frequency of use of tenses in English and German children's spontaneous speech. Child development, 49, 898-901. doi: 10.2307/1128267

Thompson, C. K. (2003). Unaccusative verb production in agrammatic aphasia: The argument structure complexity hypothesis. Journal of Neurolinguistics, 16, 151-167. doi: 10.1016/S0911-6044(02)00014-3

Thompson, C. K., Shapiro, L. P., Tait, M. E., Jacobs, B. J., Schneider, S. L., \& Ballard, K. J. (1995). A system for the linguistic analysis of agrammatic language production. Brain and Language, 51, 124-127. doi: 10.1006/brln.1995.1058

Varlokosta, S., Valeonti, N., Kakavoulia, M., Lazaridou, M., Economou, A., \& Protopapas, A. (2006). The breakdown of functional categories in Greek aphasia: Evidence from agreement, tense, and aspect. Aphasiology, 20, 723-743. doi: 10.1080/02687030500513703

Vendler, Z. (1957). Verbs and times. The Philosophical Review, 66, 143-160.

Waters, G. S., \& Caplan, D. (2005). The relationship between age, processing speed, working memory capacity, and language comprehension. Memory, 13, 403-413. doi:

$10.1080 / 09658210344000459$

Wenzlaff, M., \& Clahsen, H. (2004). Tense and agreement in German agrammatism. Brain and Language, 89, 57-68. doi: 10.1016/S0093-934X(03)00298-0

Yarbay Duman, T., \& Bastiaanse, R. (2009). Time reference through verb inflection in Turkish agrammatic aphasia. Brain and Language, 108, 30-39. doi: 10.1016/j.band1.2008.09.009

Zagona, K. (2003). Tense and anaphora: Is there a tense-specific theory of co-reference? In A. Barrs 
(Ed.), Anaphora: A Reference Guide (pp. 140-171). Oxford: Blackwell.

Zagona, K. (2013). Tense, aspect and modality. In M. D. Dikken (Ed.), The Cambridge Handbook of Generative Syntax (pp. 746-792). Cambridge: Cambridge University Press. 
Table 1. Aphasic and control participants' demographic and selected language testing data.

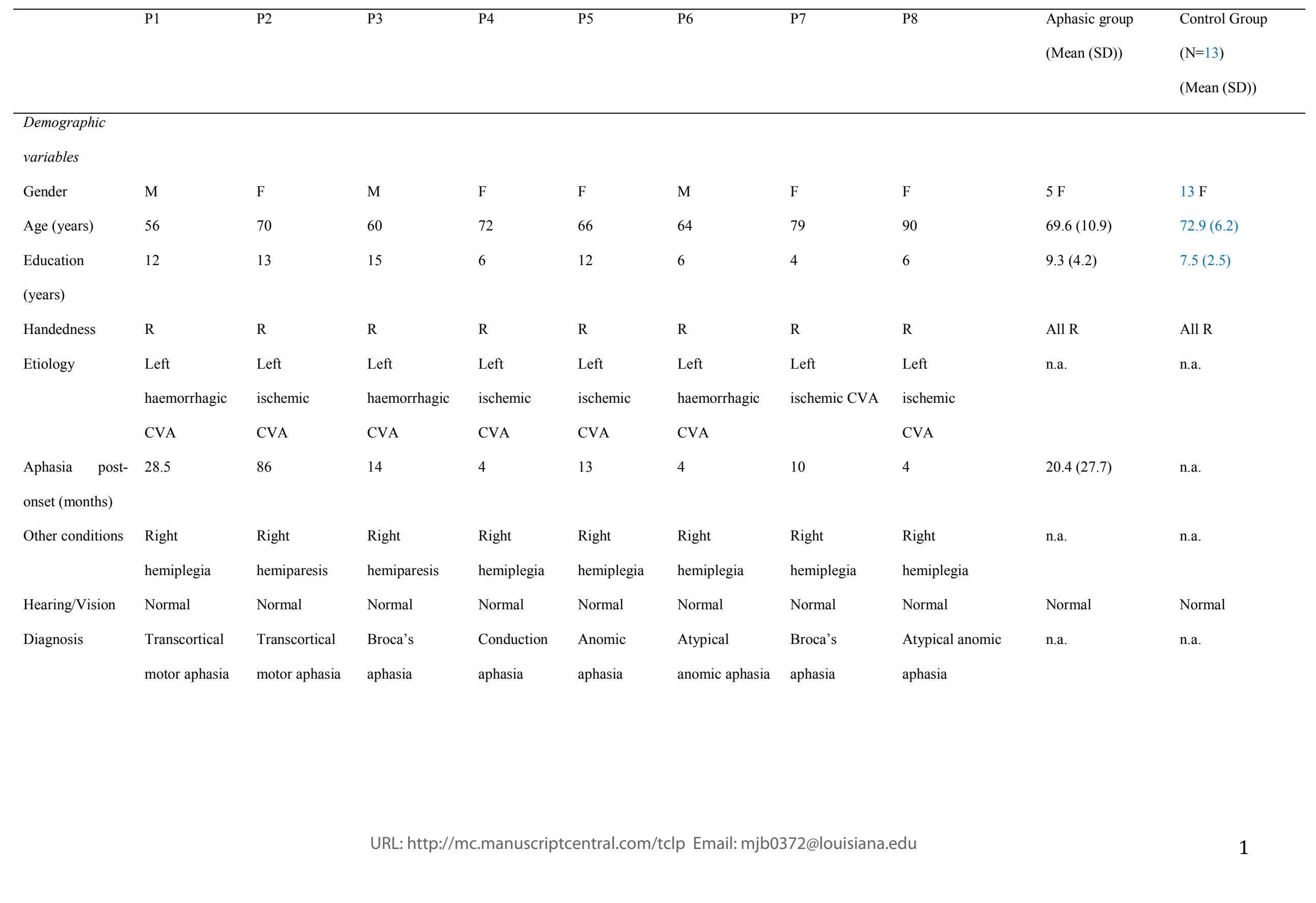




\begin{tabular}{|c|c|c|c|c|c|c|c|c|c|c|}
\hline Lesion site & Basal ganglia & Basal ganglia & $\begin{array}{l}\text { Frontal \& } \\
\text { parietal lobe }\end{array}$ & n.a. & n.a. & n.a. & n.a. & n.a. & n.a. & n.a. \\
\hline \multicolumn{11}{|c|}{ Language variables } \\
\hline $\begin{array}{l}\text { Words per } \\
\text { minute }\end{array}$ & 21 & 40.5 & 12.1 & 54.2 & 51.3 & 50.6 & 47.2 & 51.3 & $38.3(17.7)$ & $111.9(59.3)$ \\
\hline MLU & 5.2 & 5.9 & 3.7 & 7.2 & 8.4 & 6.1 & 6.2 & 8.3 & $6.1(1.6)$ & $10(1.6)$ \\
\hline \%Grammatical & 64 & 47.4 & 56.5 & 60 & 68.4 & 71.1 & 45 & 73 & $61.2(8.6)$ & $92.1(7.7)$ \\
\hline
\end{tabular}

sentences

Note 1: The (semi)spontaneous speech data of the control participants were drawn from an unpublished database of neurologically intact Greekspeaking individuals' (semi)spontaneous speech (Fyndanis, Galiussi, \& Christidou, 2014), which was analyzed following the methods and procedures described in the Methods section. To elicit speech from these healthy participants, the experimenter asked them to describe the Cookie Theft picture and to narrate an important event of their life.

Note 2: MLU = Mean Length of Utterance

Note 3: The hearing/vision data are self-reported data. 
Table 2. Examples of all conditions/combinations between different time frames and aspectual values

Time Reference condition

Past Reference Perfective $\quad$ Past Reference Imperfective

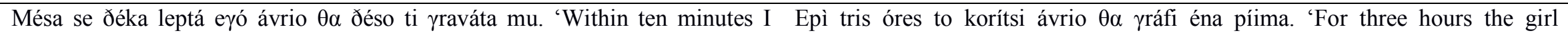

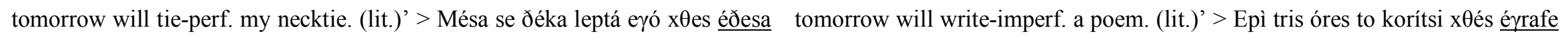

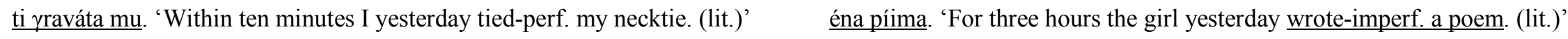

Future Reference Perfective $\quad$ Future Reference Imperfective

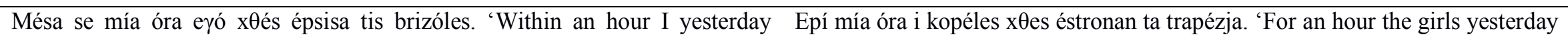

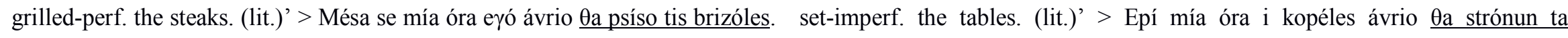
'Within an hour I tomorrow will grill-perf. the steaks. (lit.)' $\quad$ trapézja. 'For an hour the girls tomorrow will set-imperf. the tables. (lit.)'

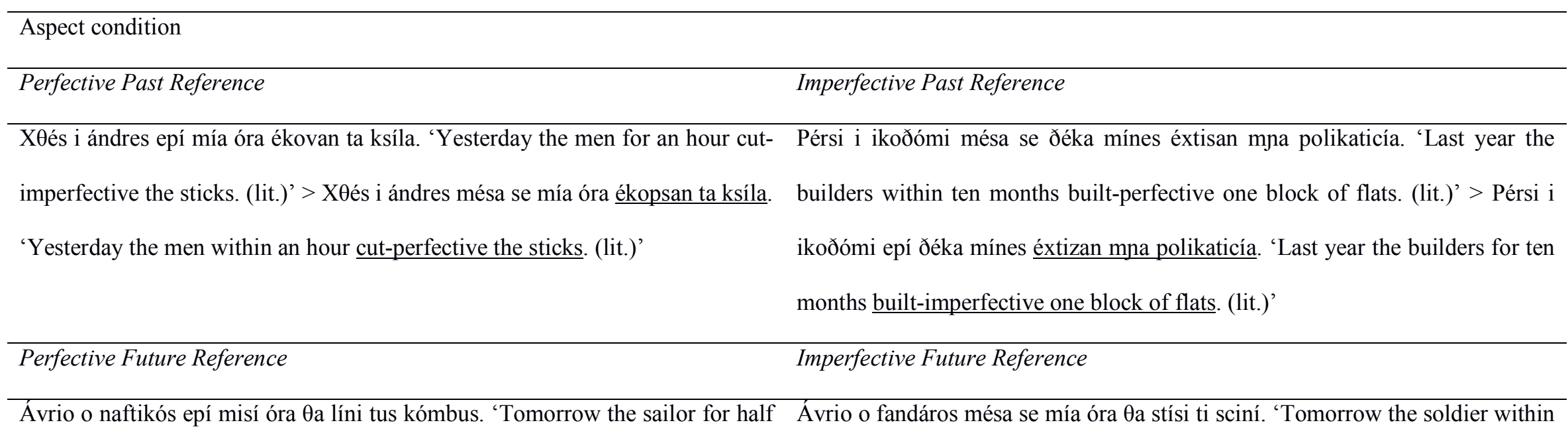


Note: Underlined are the target verb phrases that the participants were expected to produce. 
Table 3. Individual results (correct) of the aphasic participants in the Time Reference condition (broken down into four subconditions).

\begin{tabular}{llllllllll}
\hline & P1 & P2 & P3 & P4 & P5 & P6 & P7 & P8 & Total \\
\hline past perfective & $10 / 16$ & $10 / 16$ & $13 / 16$ & $13 / 16$ & $14 / 16$ & $12 / 16$ & $3 / 16$ & $7 / 16$ & $\mathbf{8 2} / \mathbf{1 2 8}$ \\
& $(63 \%)$ & $(63 \%)$ & $(81 \%)$ & $(81 \%)$ & $(88 \%)$ & $(75 \%)$ & $(19 \%)$ & $(44 \%)$ & $(\mathbf{6 4 \% )}$ \\
past imperfective & $8 / 16$ & $9 / 16$ & $14 / 16$ & $13 / 16$ & $16 / 16$ & $11 / 16$ & $0 / 16$ & $6 / 16$ & $\mathbf{7 7 / 1 2 8}$ \\
& $(50 \%)$ & $(56 \%)$ & $(88 \%)$ & $(81 \%)$ & $(100 \%)$ & $(69 \%)$ & $(0 \%)$ & $(38 \%)$ & $(\mathbf{6 0 \%})$ \\
future perfective & $14 / 16$ & $7 / 16$ & $12 / 16$ & $10 / 16$ & $15 / 16$ & $14 / 16$ & $15 / 16$ & $4 / 16$ & $\mathbf{9 1 / 1 2 8}$ \\
& $(88 \%)$ & $(44 \%)$ & $(75 \%)$ & $(63 \%)$ & $(94 \%)$ & $(88 \%)$ & $(94 \%)$ & $(25 \%)$ & $(\mathbf{7 1 \%} \%)$ \\
future imperfective & $14 / 16$ & $9 / 16$ & $11 / 16$ & $8 / 16$ & $15 / 16$ & $13 / 16$ & $16 / 16$ & $3 / 16$ & $\mathbf{8 9 / 1 2 8}$ \\
& $(88 \%)$ & $(56 \%)$ & $(69 \%)$ & $(50 \%)$ & $(94 \%)$ & $(81 \%)$ & $(100 \%)$ & $(19 \%)$ & $(\mathbf{7 0 \% )}$
\end{tabular}


Table 4. Logit mixed-effect model on aphasic participants' accuracy on Past Reference within Perfective and Imperfective Aspect contexts (Past Reference subcondition of Time Reference condition).

\begin{tabular}{lllll}
\hline Term & $\boldsymbol{\beta}$ & Standard Error & z-value & p-value \\
\hline (Intercept; Aspect=Imperfective, & 0.626 & 0.555 & 1.128 & 0.259 \\
Alternating Transitivity=No) & & & & \\
Aspect=Perfective & 0.297 & 0.405 & 0.733 & 0.464 \\
Alternating Transitivity=Yes & -0.263 & 0.416 & -0.632 & 0.527 \\
Aspect=Perfective : Alternating & -0.268 & 0.601 & -0.446 & 0.656 \\
Transitivity=Yes & & & & \\
\hline
\end{tabular}

Note: This model included the additive effect of Aspect (two levels: Perfective, Imperfective) and Alternating Transitivity (two levels: Yes, No), and the interaction between the two. The model also included a random intercept for Subjects $(\mathrm{SD}=1.317)$, and a random intercept for Items $(\mathrm{SD}=0)$ (Model 2). 
Table 5. Logit mixed-effect model on aphasic participants' accuracy on Future Reference within Perfective and Imperfective Aspect contexts (Future Reference subcondition of Time Reference condition).

\begin{tabular}{llllc}
\hline Term & $\boldsymbol{\beta}$ & Standard Error & z-value & p-value \\
\hline (Intercept; Aspect=Imperfective, & 1.269 & 0.582 & 2.181 & $<0.05$ \\
Alternating Transitivity=No) & & & \\
Aspect=Perfective & 0.127 & 0.430 & 0.294 & 0.769 \\
Alternating Transitivity=Yes & -0.299 & 0.442 & -0.677 & 0.499 \\
Aspect=Perfective : Alternating & -0.159 & 0.635 & -0.250 & 0.803 \\
Transitivity=Yes & & & & \\
\hline Note: This model included the additive effect of Aspect (two levels: Perfective, Imperfective) and
\end{tabular}

Note: This model included the additive effect of Aspect (two levels: Perfective, Imperfective) and Alternating Transitivity (two levels: Yes, No), and the interaction between the two. The model also included a random intercept for Subjects $(\mathrm{SD}=1.350)$, and a random intercept for Items $(\mathrm{SD}=0)$ (Model 2). 
Table 6. Logit mixed-effect model on healthy participants' $(\mathrm{N}=103)$ accuracy on Past Reference within Perfective and Imperfective Aspect contexts (Past Reference subcondition of Time Reference condition).

\begin{tabular}{llllc}
\hline Term & $\boldsymbol{\beta}$ & Standard Error & z-value & p-value \\
\hline (Intercept; Aspect=Imperfective, & 10.096 & 1.088 & 9.278 & $<0.001$ \\
Alternating Transitivity=No) & & & & \\
Aspect=Perfective & 0.314 & 0.505 & 0.621 & 0.535 \\
Alternating Transitivity=Yes & -0.250 & 0.522 & -0.478 & 0.633 \\
Aspect=Perfective : Alternating & 0.022 & 0.758 & 0.029 & 0.977 \\
Transitivity=Yes & & & & \\
\hline Note: This model included the additive effect of Aspect (two levels: Perfective, Imperfective) and
\end{tabular}

Note: This model included the additive effect of Aspect (two levels: Perfective, Imperfective) and Alternating Transitivity (two levels: Yes, No), and the interaction between the two. The model also included a random intercept for Subjects $(\mathrm{SD}=7.426)$, and a random intercept for Items $(\mathrm{SD}=$ 0.758) (Model 2). 
Table 7. Logit mixed-effect model on healthy participants' $(\mathrm{N}=103)$ accuracy on Future Reference within Perfective and Imperfective Aspect contexts (Future Reference subcondition of Time Reference condition).

\begin{tabular}{lllll}
\hline Term & $\boldsymbol{\beta}$ & Standard Error & z-value & p-value \\
\hline (Intercept; Aspect=Imperfective, & 10.231 & 1.078 & 9.492 & $<0.001$ \\
Alternating Transitivity=No) & & & & \\
Aspect=Perfective & 0.153 & 0.380 & 0.401 & 0.688 \\
Alternating Transitivity=Yes & -0.709 & 0.387 & -1.833 & 0.067 \\
Aspect=Perfective : Alternating & 0.322 & 0.559 & & 0.576 \\
Transitivity=Yes & & & & 0.565 \\
\end{tabular}

Note: This model included the additive effect of Aspect (two levels: Perfective, Imperfective) and Alternating Transitivity (two levels: Yes, No), and the interaction between the two. The model also included a random intercept for Subjects $(\mathrm{SD}=7.612)$, and a random intercept for Items $(\mathrm{SD}=$ 0.418) (Model 2). 
Table 8. Additional linear models on healthy participants' $(\mathrm{N}=103)$ accuracy on Past Reference within Perfective and Imperfective Aspect contexts (Past Reference subcondition of Time Reference condition).

\begin{tabular}{|c|c|c|c|c|}
\hline Term & $\boldsymbol{\beta}$ & Standard Error & z-value & p-value \\
\hline (Intercept; Aspect=Imperfective) & -1.873 & 1.286 & -1.46 & 0.145 \\
\hline Aspect $=$ Perfective & 0.074 & 1.867 & 0.04 & 0.968 \\
\hline Working Memory & 0.357 & 0.115 & 3.11 & $<0.01^{*}$ \\
\hline Aspect=Perfective : Working Memory & 0.015 & 0.171 & 0.09 & 0.932 \\
\hline (Intercept; Aspect=Imperfective) & 9.950 & 3.295 & 3.02 & $<0.01 *$ \\
\hline Aspect=Perfective & 0.249 & 4.876 & 0.05 & 0.959 \\
\hline Age & -0.110 & 0.045 & -2.47 & $0.014^{*}$ \\
\hline Aspect=Perfective : Age & -0.001 & 0.066 & -0.01 & 0.990 \\
\hline (Intercept; Aspect=Imperfective) & -0.102 & 0.993 & -0.10 & 0.918 \\
\hline Aspect=Perfective & 0.302 & 1.438 & 0.21 & 0.834 \\
\hline Education & 0.280 & 0.104 & 2.68 & $<0.01 *$ \\
\hline Aspect=Perfective : Education & -0.014 & 0.151 & -0.09 & 0.926 \\
\hline
\end{tabular}

Note: Three generalized linear models were fitted to the healthy participants' dataset of the Past Reference subcondition of the Time Reference condition. The first model included the additive effect of Aspect (more precisely, aspectual context) (two levels: Perfective, Imperfective) and verbal Working Memory (continuous variable), and the interaction between the two. The second model included the additive effect of Aspect (two levels: Perfective, Imperfective) and Age (continuous variable), and the interaction between the two. The third model included the additive effect of Aspect (two levels: Perfective, Imperfective) and (years of formal) Education (continuous URL: http://mc.manuscriptcentral.com/tclp Email: mjb0372@louisiana.edu 
variable), and the interaction between the two. 
Table 9. Additional linear models on healthy participants' $(\mathrm{N}=103)$ accuracy on Future Reference within Perfective and Imperfective Aspect contexts (Future Reference subcondition of Time Reference condition).

\begin{tabular}{|c|c|c|c|c|}
\hline Term & $\beta$ & Standard Error & z-value & p-value \\
\hline (Intercept; Aspect=Imperfective) & -1.900 & 1.261 & -1.51 & 0.132 \\
\hline Aspect $=$ Perfective & 0.216 & 1.823 & 0.12 & 0.906 \\
\hline Working Memory & 0.351 & 0.110 & 3.18 & $0.002 *$ \\
\hline Aspect=Perfective : Working Memory & 0.003 & 0.163 & 0.02 & 0.985 \\
\hline (Intercept; Aspect=Imperfective) & 9.973 & 3.232 & 3.09 & $<0.01 *$ \\
\hline Aspect $=$ Perfective & 0.723 & 4.954 & 0.15 & 0.884 \\
\hline Age & -0.111 & 0.044 & -2.54 & $0.011^{*}$ \\
\hline Aspect $=$ Perfective : Age & -0.007 & 0.066 & -0.10 & 0.918 \\
\hline (Intercept; Aspect=Imperfective) & -0.407 & 0.987 & -0.41 & 0.680 \\
\hline Aspect $=$ Perfective & 0.126 & 1.434 & 0.09 & 0.930 \\
\hline Education & 0.308 & 0.108 & 2.86 & $<0.05^{*}$ \\
\hline Aspect=Perfective : Education & 0.012 & 0.160 & 0.08 & 0.939 \\
\hline
\end{tabular}

Note: Three generalized linear models were fitted to the healthy participants' dataset of the Future Reference subcondition of the Time Reference condition. The first model included the additive effect of Aspect (more precisely, aspectual context) (two levels: Perfective, Imperfective) and verbal Working Memory (continuous variable), and the interaction between the two. The second model included the additive effect of Aspect (two levels: Perfective, Imperfective) and Age (continuous variable), and the interaction between the two. The third model included the additive 
effect of Aspect (two levels: Perfective, Imperfective) and (years of formal) Education (continuous variable), and the interaction between the two. 
Table 10. Individual results (correct) of the aphasic participants in the Aspect condition.

\begin{tabular}{lllllllllll}
\hline & $\mathrm{P} 1$ & $\mathrm{P} 2$ & $\mathrm{P} 3$ & $\mathrm{P} 4$ & $\mathrm{P} 5$ & $\mathrm{P} 6$ & $\mathrm{P} 7$ & $\mathrm{P} 8$ & Total \\
\hline perfective past & $6 / 16$ & $10 / 16$ & $14 / 16$ & $3 / 16$ & $12 / 16$ & $5 / 16$ & $9 / 16$ & $10 / 16$ & $\mathbf{6 9 / 1 2 8}$ \\
& $(38 \%)$ & $(63 \%)$ & $(88 \%)$ & $(19 \%)$ & $(75 \%)$ & $(31 \%)$ & $(56 \%)$ & $(63 \%)$ & $\mathbf{( 5 4 \% )}$ \\
imperfective past & $11 / 16$ & $5 / 16$ & $7 / 16$ & $7 / 16$ & $7 / 16$ & $9 / 16$ & $4 / 16$ & $4 / 16$ & $\mathbf{5 4 / 1 2 8}$ \\
& $(69 \%)$ & $(31 \%)$ & $(44 \%)$ & $(44 \%)$ & $(44 \%)$ & $(56 \%)$ & $(25 \%)$ & $(25 \%)$ & $\mathbf{( 4 2 \% )}$ \\
perfective future & $0 / 16$ & $4 / 16$ & $15 / 16$ & $1 / 16$ & $0 / 16$ & $3 / 16$ & $8 / 16$ & $10 / 16$ & $\mathbf{4 1 / 1 2 8}$ \\
imperfective future & $(0 \%)$ & $(25 \%)$ & $(94 \%)$ & $(6 \%)$ & $(0 \%)$ & $(19 \%)$ & $(50 \%)$ & $(63 \%)$ & $\mathbf{( 3 2 \% )}$ \\
& $10 / 16$ & $3 / 16$ & $11 / 16$ & $1 / 16$ & $4 / 16$ & $8 / 16$ & $1 / 16$ & $0 / 16$ & $\mathbf{3 8} / \mathbf{1 2 8}$ \\
\hline
\end{tabular}


Table 12. Logit mixed-effect model on aphasic participants' accuracy on Perfective and Imperfective Aspect within a Future Reference context.

\begin{tabular}{llllc}
\hline Term & $\boldsymbol{\beta}$ & Standard Error & z-value & p-value \\
\hline (Intercept; Aspect=Imperfective) & -1.073 & 0.632 & -1.699 & 0.089 \\
Aspect=Perfective & -0.502 & 1.140 & -0.440 & 0.660 \\
Alternating Transitivity=Yes & -0.306 & 0.444 & 0.688 & 0.492 \\
Aspect=Perfective : Alternating & 0.680 & 0.658 & 1.033 & 0.301 \\
Transitivity=Yes & & & &
\end{tabular}

Note: This model included the additive effect of Aspect (two levels: Perfective, Imperfective) and Alternating Transitivity (two levels: Yes, No), and the interaction between the two. The model also included a random intercept for Subjects $(S D=1.497)$, a random intercept for Items $(S D=0)$, and a by-Subject random slope of Aspect (Model 1). 
Table 13. Logit mixed-effect model on healthy participants' $(N=103)$ accuracy on Perfective and Imperfective Aspect within a Past Reference context.

\begin{tabular}{lllll}
\hline Term & $\boldsymbol{\beta}$ & Standard Error & z-value & p-value \\
\hline (Intercept; Aspect=Imperfective) & 5.174 & 0.818 & 6.328 & $<0.001$ \\
Aspect=Perfective & 0.180 & 0.891 & 0.202 & 0.840 \\
Alternating Transitivity=Yes & -0.018 & 0.460 & -0.039 & 0.969 \\
Aspect=Perfective : Alternating & 0.991 & 0.672 & 1.474 & 0.140 \\
Transitivity=Yes & & & &
\end{tabular}

Note: This model included the additive effect of Aspect (two levels: Perfective, Imperfective) and Alternating Transitivity (two levels: Yes, No), and the interaction between the two. The model also included a random intercept for Subjects $(\mathrm{SD}=3.987)$, a random intercept for Items $(\mathrm{SD}=0.776)$, and a by-Subject random slope of Aspect (Model 1). 
Table 14. Logit mixed-effect model on healthy participants' $(N=103)$ accuracy on Perfective and Imperfective Aspect within a Future Reference context.

\begin{tabular}{llllc}
\hline Term & $\boldsymbol{\beta}$ & Standard Error & z-value & p-value \\
\hline (Intercept; Aspect=Imperfective) & 3.516 & 0.482 & 7.293 & $<0.001$ \\
Aspect=Perfective & 0.459 & 0.533 & 0.861 & 0.389 \\
Alternating Transitivity=Yes & 0.233 & 0.309 & 0.755 & 0.450 \\
Aspect=Perfective : Alternating & -0.296 & 0.439 & -0.674 & 0.500 \\
Transitivity=Yes & & & &
\end{tabular}

Note: This model included the additive effect of Aspect (two levels: Perfective, Imperfective) and Alternating Transitivity (two levels: Yes, No), and the interaction between the two. The model also included a random intercept for Subjects $(S D=3.168)$, a random intercept for Items $(S D=0.472)$, and a by-Subject random slope of Aspect (Model 1). 
Table 15. Additional linear models on healthy participants' $(N=103)$ accuracy on Perfective and Imperfective Aspect within a Past Reference context.

\begin{tabular}{|c|c|c|c|c|}
\hline Term & $\boldsymbol{\beta}$ & Standard Error & z-value & p-value \\
\hline (Intercept; Aspect=Imperfective) & -3.156 & 1.104 & -2.86 & $<0.05^{*}$ \\
\hline Aspect $=$ Perfective & 1.291 & 1.530 & 0.84 & 0.399 \\
\hline Working Memory & 0.324 & 0.076 & 4.25 & $<0.001 *$ \\
\hline Aspect=Perfective : Working Memory & -0.046 & 0.109 & -0.42 & 0.672 \\
\hline (Intercept; Aspect=Imperfective) & 7.497 & 1.682 & 4.46 & $<0.001 *$ \\
\hline Aspect $=$ Perfective & -0.811 & 2.406 & -0.34 & 0.736 \\
\hline Age & -0.096 & 0.025 & -3.88 & $<0.001 *$ \\
\hline Aspect=Perfective : Age & 0.021 & 0.035 & 0.61 & 0.545 \\
\hline (Intercept; Aspect=Imperfective) & -2.416 & 0.902 & -2.68 & $<0.01 *$ \\
\hline Aspect $=$ Perfective & 1.728 & 1.235 & 1.40 & 0.162 \\
\hline Education & 0.367 & 0.086 & 4.29 & $<0.001 *$ \\
\hline Aspect $=$ Perfective $:$ Education & -0.111 & 0.116 & -0.96 & 0.339 \\
\hline
\end{tabular}

Note: Three generalized linear models were fitted to the healthy participants' dataset for the Aspect within a past reference context condition. The first model included the additive effect of Aspect (two levels: Perfective, Imperfective) and verbal Working Memory (continuous variable), and the interaction between the two. The second model included the additive effect of Aspect (two levels: Perfective, Imperfective) and Age (continuous variable), and the interaction between the two. The third model included the additive effect of Aspect (two levels: Perfective, Imperfective) and (years of formal) Education (continuous variable), and the interaction between the two. 
Table 16. Additional linear models on healthy participants' $(N=103)$ accuracy on Perfective and Imperfective Aspect within a Future Reference context.

\begin{tabular}{|c|c|c|c|c|}
\hline Term & $\beta$ & Standard Error & z-value & p-value \\
\hline (Intercept; Aspect=Imperfective) & -3.028 & 1.053 & -2.88 & $<0.01 *$ \\
\hline Aspect $=$ Perfective & 1.355 & 1.444 & 0.94 & 0.348 \\
\hline Working Memory & 0.295 & 0.070 & 4.24 & $<0.001 *$ \\
\hline Aspect=Perfective : Working Memory & -0.056 & 0.097 & -0.58 & 0.564 \\
\hline (Intercept; Aspect=Imperfective) & 6.772 & 1.451 & 4.67 & $<0.001^{*}$ \\
\hline Aspect $=$ Perfective & -1.315 & 1.974 & -0.67 & 0.510 \\
\hline Age & -0.089 & 0.022 & -4.06 & $<0.001^{*}$ \\
\hline Aspect $=$ Perfective : Age & 0.029 & 0.030 & 0.96 & 0.340 \\
\hline (Intercept; Aspect=Imperfective) & -2.410 & 0.859 & -2.80 & $<0.01 *$ \\
\hline Aspect $=$ Perfective & 1.519 & 1.175 & 1.29 & 0.196 \\
\hline Education & 0.337 & 0.076 & 4.41 & $<0.001^{*}$ \\
\hline Aspect=Perfective : Education & -0.092 & 0.105 & -0.88 & 0.378 \\
\hline
\end{tabular}

Note: Three generalized linear models were fitted to the healthy participants' dataset for the Aspect within a future reference context condition. The first model included the additive effect of Aspect (two levels: Perfective, Imperfective) and verbal Working Memory (continuous variable), and the interaction between the two. The second model included the additive effect of Aspect (two levels: Perfective, Imperfective) and Age (continuous variable), and the interaction between the two. The third model included the additive effect of Aspect (two levels: Perfective, Imperfective) and (years of formal) Education (continuous variable), and the interaction between the two. 


\section{Appendix 1}

$\underline{\text { Propositions included in the sentence completion task (selection) }}$

1. $\mathrm{x} \theta$ es i maقítries amésos éxasan to enðiaféron tus ${ }^{1}$

'yesterday the students-fem immediately lost-perfective the interest their' (lit.)

2. epí misí óra o ádras $x \theta e s$ ékove ta ksíla

'for an hour the man yesterday cut-imperfective the sticks' (lit.)

3. ávrio i kopéles epí mía óra $\theta$ a strónun ta krevátça

'tomorrow the girls for an hour will make-imperfective the beds' (lit.)

4. mésa se mía óra i đaskáles $x \theta e s$ édisan ta peðjá

'within an hour the teachers-fem yesterday dressed up the children' (lit.)

5. xӨes i komótries epí misí óra éluzan tus pelátes

'yesterday the hairdressers for half an hour bathed-imperfective the customers' (lit.)

6. epí éksi mínes o ikoðómos pérsi éxtize to spíti

'for six months the builder last year built-imperfective the house' (lit.)

7. ávrio i cipurí mésa se đío óres $\theta$ a skápsun ton cípo

'tomorrow the gardeners within two hours will dig the garden' (lit.)

8. mésa se mía óra i fílaces $x \theta$ es ézvisan ta fóta

'within an hour the security guards yesterday turned off the lights' (lit.)

\footnotetext{
${ }^{1}$ One could argue that, in proposition (1), the verb éxasan 'lost' does not refer to an accomplishment, because the adverb amésos 'immediately', which precedes the verb, prevents the event from being seen as incremental or gradual. However, it is clear that the event of 'losing interest' has an endpoint (which is the very moment of completely losing interest in something) and is also incremental or gradual. There is across-subject variation in the speed of losing interest in a given topic. The adverb amésos 'immediately' does not have a literal meaning in proposition (1); its use implies that the students lost interest in the topic very quickly.
}

URL: http://mc.manuscriptcentral.com/tclp Email: mjb0372@louisiana.edu 
9. xӨes o naftikós epí péde leptá éline ton kóbo

'yesterday the sailor for five minutes untied-imperfective the knot' (lit.)

10. epí đéka leptá o yabrós ávrio $\theta$ a đéni ti yraváta tu

'within ten minutes the groom tomorrow will tie-imperfective his necktie' (lit.)

11. ávrio to ayóri mésa se misí óra $\theta a$ stísi ti sciní

'tomorrow the boy within half an hour will set up-perfective the tent' (lit.)

12. mésa se mía óra i psaráðes ávrio $\theta a$ psísun ta psárja

'within an hour the fishermen tomorrow will grill the fishes' (lit.)

13. xӨes i ciría mésa se mía óra éplekse to kaskól

'yesterday the woman within an hour knitted the scarf' (lit.)

14. epí mía óra i ciría ávrio $\theta a$ rávi tin blúza

'for an hour the woman tomorrow will sew the sweater' (lit.)

15. mésa se mía óra ta korítsça ávrio $\theta$ a yrápsun to píima

'within an hour the girls tomorrow will write the poem' (lit.)

16. ávrio i jinéces epí mía óra $\theta$ a spázun ta amíyðala

'tomorrow the women for an hour will smash the almonds' (lit.) 


\section{Appendix 2}

$\underline{\text { Syntactic classification of experimental verbs }}$

Verbs of alternating transitivity

1. ðéno (e.g., éðesa ti sáltsa (me alévri) - i sáltsa éðese apó móni tis)

'to tie/to thicken' 'I thickened the sauce with flour' - 'The sauce was thickened by itself'

2. zvíno (e.g., o pirosvéstis zvíni ti fotçá - i fotçá zvíni apó móni tis)

'extinguish/quench' 'The firefighter extinguishes the fire' - 'The fire is quenched by itself'

3. spázo (e.g., éspasa to dzámi - to dzámi éspase apó móno tu)

'to break' 'I broke the window' - 'The window broke by itself'

4. xáno (e.g., éxasa ta kliðjá - ta kliðjá xáOikan apó móna tus)

'to lose' 'I lost the keys' - 'The keys were lost by themselves'

5. líno (e.g., élisa ta korðóna mu - ta korðóna mu líikan apó móna tus)

'to untie' 'I untied my laces' - 'My laces were untied by themselves'

6. psíno (e.g., épsisa to kréas - to kréas psïike apó móno tu)

'to cook' 'I cooked the meat' - 'The meat was cooked by itself'

7. kóvo (e.g., ékopsa tin klostí - i klostí kópike apó móni tis)

'to cut' 'I cut the thread' - 'The thread was cut by itself'

Verbs with a single theta-grid (transitive verbs only)

8. lúzo 'to bathe'

9. díno 'to dress up'

10. skávo 'to dig'

11. xtízo 'to build'

12. pléko 'to knit'

13. rávo 'to sew'

14. stíno 'to set up'

URL: http://mc.manuscriptcentral.com/tclp Email: mjb0372@louisiana.edu 

15. stróno 'to set/to make'
16. yráfo 'to write' 


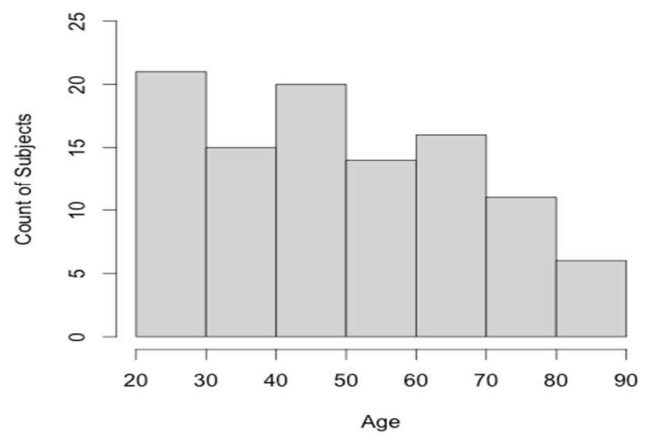

Figure 1. Distribution of healthy participants across lifespan decades. 


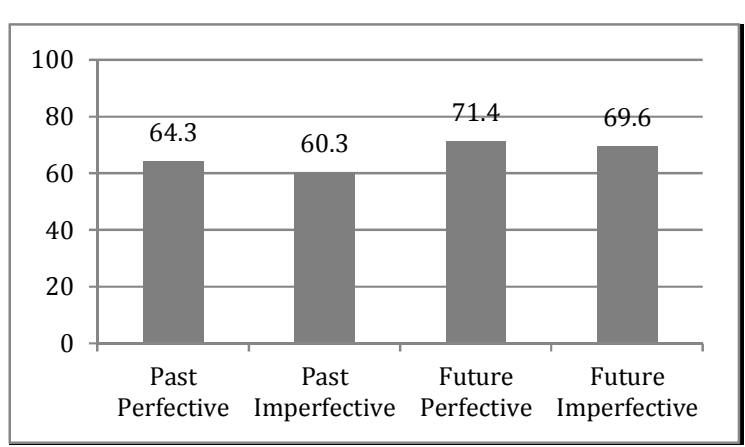

Figure 2. Performance (\%correct) of aphasic participants on the four subconditions of the Time Reference condition. 


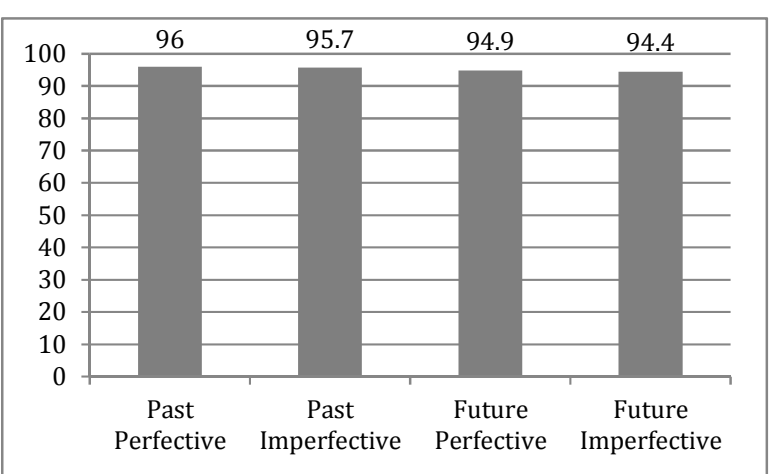

Figure 3. Performance (\%correct) of healthy participants on the four subconditions of the Time Reference condition. 


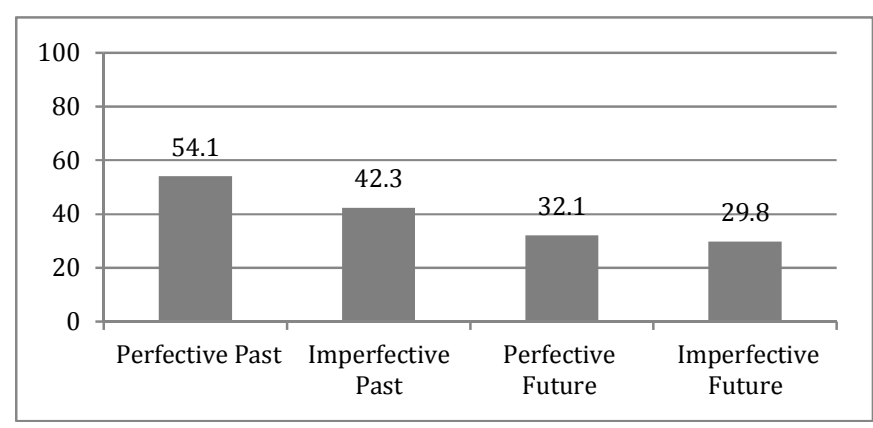

Figure 4. Performance (\%correct) of aphasic participants on the four subconditions of the Aspect condition. 


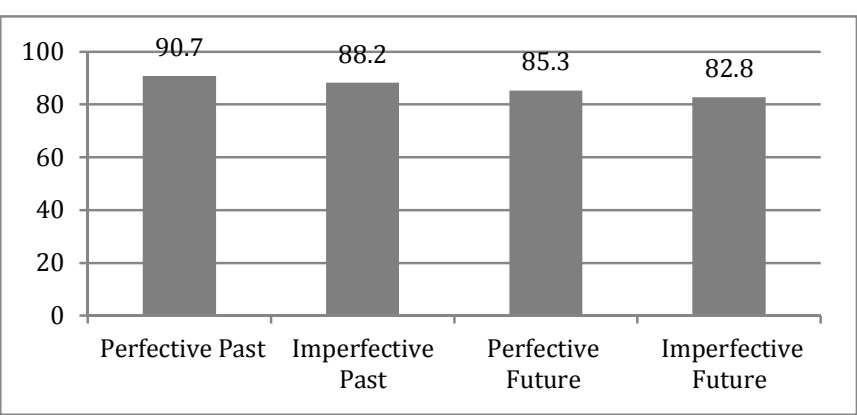

Figure 5. Performance (\%correct) of healthy participants on the four subconditions of the Aspect condition. 